\title{
Performance Appraisal Management System of University Administrators Based on Hybrid Cloud
}

\author{
XiuQing Wu $(\mathbb{D}$ \\ Minnan Science and Technology University, Quanzhou, Fujian Province 362332, China \\ Correspondence should be addressed to XiuQing Wu; xiuqing@mku.edu.cn
}

Received 9 November 2021; Revised 29 November 2021; Accepted 9 December 2021; Published 7 January 2022

Academic Editor: Baiyuan Ding

Copyright ( 2022 XiuQing Wu. This is an open access article distributed under the Creative Commons Attribution License, which permits unrestricted use, distribution, and reproduction in any medium, provided the original work is properly cited.

\begin{abstract}
Aiming at the problems of poor functionality, high occupancy, and low real-time performance of the currently designed performance appraisal management system for university administrators, a performance appraisal management system for university administrators based on hybrid cloud is designed. According to the characteristics of hybrid cloud technology, the overall functional requirements and feasibility of the system are analyzed, and the assessment scheme of administrative personnel according to the provisions of relevant documents is analyzed. The performance appraisal index system is designed using an analytic hierarchy process. Using the hybrid cloud architecture and B/S mode based on each component as a service model and J2EE development framework, the basic information management subsystem of administrative personnel, performance appraisal information management subsystem, information analysis and data mining subsystem, and platform system management subsystem are developed. Using XML technology and database technology, the system is integrated with the performance appraisal management system of administrators in colleges and universities. Through the design of data flow diagram and E- $\mathrm{R}$ diagram, the design of performance appraisal management system for university administrators based on hybrid cloud is realized. The experimental results show that the proposed method has good functionality, can effectively reduce the system occupancy, and can improve the real-time performance of the system.
\end{abstract}

\section{Introduction}

The annual performance appraisal of university administrators is one of the basic works of examining administrators and an important content of cadre management, and the appraisal result is one of the important bases for the organization/personnel department to hire and employ cadres. However, with the deepening of the internal personnel system reform in colleges and universities in China, it is urgent to establish and perfect the performance appraisal system, implement the performance appraisal, and establish the incentive mechanism in the development and management of human resources in colleges and universities, and it is also the foundation for a university to maintain/ consolidate and develop. As colleges and universities cultivate high-level and high-quality talents, they are facing unprecedented development opportunities and challenges. People pay more and more attention to the theory and practice of human resource management, and performance management has gradually developed into a widely recognized human resource management behavior [1-3]. The performance appraisal of university administrators is difficult to effectively evaluate their work performance. The traditional performance appraisal method cannot effectively meet the needs of human resource management [4-6]. With the deepening of the strategy of rejuvenating the country through science and education, higher education has developed rapidly. As an important part of human resources in colleges and universities, managers shoulder the important task of serving the teachers and students of the whole university, and their management level is becoming more and more important [7]. Colleges and universities are different from enterprises. How to apply the good practice of performance management in enterprises to colleges and universities continuously strengthen the performance appraisal of university administrators, improve the overall 
quality of managers, and reasonably measure the performance, and work efficiency of managers is of great significance to the performance appraisal of colleges and universities.

At present, the research on performance appraisal management system has also made great progress. Nobari et al. [8] designed the staff performance evaluation system of the Iranian National Library and Archives. Using the soft operation research method, combined with the soft system methodology and important performance analysis method, the challenges of employee performance evaluation are determined. The opinions and experience of system stakeholders are used, and the important performance analysis methods are used to determine and prioritize improvement actions. The system designed by this method has certain effectiveness. Demartini and Otley [9] designed a beyond performance management system. Using loose coupling theory, this study studies the relationship types in performance management system. A performance management system coupling index is conceptually developed and verified with a sample of 140 managers operating in different industries. This method designs the system to provide the best results for effectiveness and innovation. However, the above methods still have the problems of poor system functionality, high occupancy rate, and low real-time performance.

To optimize the functionality of the performance management system, the CPU occupancy rate is reduced and the real-time performance of the system is improved, and this study designed a new hybrid cloud-based performance appraisal management system for university managers. The basic information management subsystem, performance evaluation information management subsystem, information analysis subsystem, data mining subsystem, and platform system management subsystem are designed through the hybrid cloud architecture and B/S mode of component as a service model and J2EE development framework. By analyzing the overall functional requirements of the system, the evaluation scheme, and feasibility of management personnel, the performance evaluation index system is designed using an analytic hierarchy process. Using hybrid cloud architecture, B/S mode, J2EE development framework, XML technology, and database technology, through the design of data flow chart and E-R diagram, the performance appraisal management system of university administrators is developed. To verify the application effectiveness of the research system, a simulation experiment is designed to test the system. The experimental results show that the system has an ideal application function and low occupancy rate and can effectively improve the real-time performance of the system.

\section{Related Technologies}

2.1. Hybrid Cloud Technology. At present, the concept of hybrid cloud widely accepted in the industry comes from the definition of cloud computing released by NIST, which gives cloud computing five characteristics, 3 business models, and 4 deployment models. In particular, five major features are resource pooling, on-demand self-service, broadband network access, rapid flexibility, and measurable services; three types of business models are IaaS (infrastructure as service), PaaS (platform as service), and SaaS (software as service); and four types of deployment models are public cloud, community cloud, private cloud, and hybrid cloud. Hybrid cloud is a combination of several other cloud deployment patterns that support data sharing, automated deployment, flexible migration, and on-demand scaling of customer applications across the cloud. The main business drivers for hybrid clouds are cost savings, on-demand capacity expansion, disaster preparedness, and accelerated deployment of new services.

The hybrid cloud can be configured as either a public cloud environment such as Amazon, Alibaba, or Tencent, or a private cloud environment based on the OpenStack platform, or a hybrid cloud environment with multiple public and private clouds. Service organizations may select cloud computing and cloud storage services of different types and technologies based on the specific circumstances such as resources, costs, and risks, and may achieve unified management of the entire cloud environment, isomorphism of heterogeneous cloud platform resources, and crossplatform collaborative work of businesses. The hybrid cloud interface of this layer can implement the uniform encapsulation and protocol conversion of the underlying cloud services, adapt to the development interfaces of different cloud service providers, and provide a standardized cloud environment for the upper platform. By constructing a unified base cloud service pool, the differences between different technologies and protocols can be eliminated effectively, and the heterogeneous computing and storage resources can be integrated.

Hybrid cloud is a combination of at least one private cloud and at least one infrastructure based on public cloud, which generates an environment, provides transparent user access to hybrid cloud, and has dynamic scalability to manage unbalanced requirements [10-12]. Its basic model is the software as a service (SaaS) model. On this basis, the following models emerged: every component as a service (XaaS), infrastructure as a service (IaaS), platform as a service (PaaS), etc. "Each component as a service" is an ecosystem delivered in the form of components. The component is a ready-made, end-to-end independent business function module. The meaning of XaaS is to make resources consumable, which has become the core concept of hybrid cloud computing. The cloud provides complete components, as shown in Figure 1.

2.2. XML Technology. XML is a language developed by the World Wide Web Consortium (W3C) to describe the structure of the organization and arrangement of data in data documents. It defines a general syntax for tagging data using simple, easy-to-understand tags and provides a standard format for computer documents. The data contained in an XML document are a text string surrounded by text labels that describe the data. Data and tags have a special unit called an element. XML is a meta-markup language for text documents, so you are free to define tags in XML to adequately express the content of the document. 


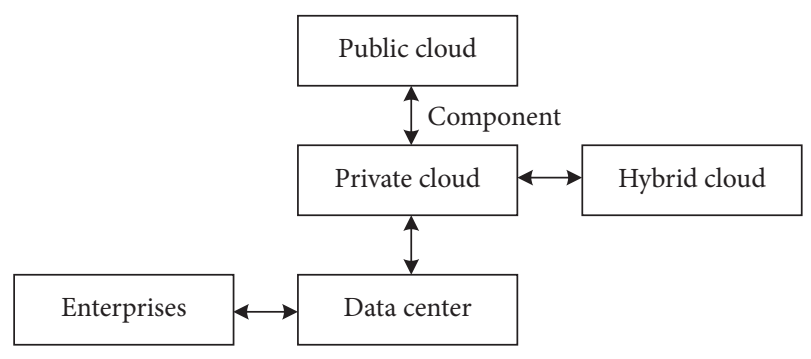

FIGURE 1: Cloud provides complete components.

The main advantage of Extensible Markup Language (XML) is its universality. It has an unshakable position in the IT field. It is difficult to imagine an important application that does not use XML to save its configuration file or data file [13-15]. XML has two main applications: the first is to use XML to express the underlying data, such as configuration files; the second is to use XML to add metadata to documents. One of the goals of XML is to completely separate data from its display. The same data can be displayed in different ways. When data are transmitted through the Internet, the bandwidth will not be wasted on the style information of the transmitted data. The main advantage of XML is not the display mode with embedded data like HTML. It separates the data from the display mode, which is very useful to realize the data independence of interface program.

\section{Demand Analysis of Performance Appraisal Management System for University Administrators}

Demand analysis is the key stage of developing the performance appraisal management system for university administrators. It is a process of continuous understanding and gradual refinement. It provides the basis for the physical scheme design in the next stage, which is mainly reflected in the two aspects of "physical demand" and "expressing demand."

3.1. Functional Requirement Analysis. System analysis focuses on the analysis from the perspective of the whole business process. Its main task is to investigate the current system and assessment system, classify and sort out the documents obtained in the investigation, analyze the overall management status and information processing process within the organization, and provide the required data for system development. From the overall performance analysis, the administrative personnel assessment management system has the following requirements:

(1) Accuracy rate: this is an important indicator to measure the system performance. The evaluation indicators of various administrative links of administrative personnel should be accurate; otherwise, it will affect the objectivity and impartiality of the assessment and lose the significance of the system development [16-18].
(2) Scalability: it refers to the expansion of system design functions. The functions realized by the design and development of the system are not limited to the evaluation between administrators and leaders, but also include the evaluation of service objects, and finally realize the "three-level" evaluation system.

(3) Ease of use: the installation, configuration, and maintenance of the system should be simple and convenient, with good user interface, convenient for all kinds of users, and convenient for system transplantation.

(4) Fault tolerance and robustness: on the one hand, the system itself has security performance requirements. On the other hand, when users operate, they can handle corresponding errors and give prompts or warnings, which can not affect the normal operation of the system.

3.2. Assessment Scheme Analysis. According to the provisions of relevant documents, based on the analysis of the original evaluation scheme of administrative personnel in colleges and universities, a set of administrative personnel evaluation schemes in line with the current work reality and development needs of colleges and universities is designed to provide a basis for the functional design of administrative personnel evaluation management system.

\subsubsection{Assessment Principle and Organization}

(1) The annual assessment shall adhere to the principles of objectivity, impartiality, democracy, and openness, and pay attention to the performance of morality and talent and work performance.

(2) The college sets up an assessment leading group to lead the assessment work of the whole school. The leader of the institute in charge of personnel work shall serve as the leader, and the deputy leader shall serve as the leader of the institute in charge of teaching work. The members are composed of 10 heads of the party and government office, organization department, personnel office, academic affairs office, discipline inspection commission (supervision office), trade union, logistics office, student work office, and staff representatives. The assessment is organized, guided, and supervised, the assessment results are reviewed, and the major problems encountered in the assessment are solved. The assessment leading group of the college has an assessment office, which is located in the personnel department, and the daily affairs are specifically undertaken by the personnel department.

(3) Each department establishes a service object assessment team composed of party and government leaders, faculty representatives, and student representatives. The main person in charge of each department acts as the leader of the assessment team. The members of the assessment team are required to report to the assessment office of the college for 
review and filing [19-21]. The representatives of the service object assessment team and the examinee have the relationship of being served and serving, which should be representative and extensive. Before the assessment, the members of the service object assessment team should widely solicit the opinions of the faculty and staff of their department or the students of their class and evaluate the examinee objectively, fairly, and truthfully.

\subsubsection{Assessment Scope and Objects}

(1) The formal managerial personnel in colleges and universities and the managerial personnel appointed according to labor contracts shall participate in the annual performance assessment.

(2) Those who leave their posts (retire) due to illness (except for work-related injuries), private affair leave, going abroad to visit relatives, and nonpublic suspension of study for more than half a year or (retire) before the end of June of the current year shall not participate in the annual assessment. The early retirees of colleges and universities shall not participate in the annual performance assessment.

3.2.3. Assessment Content. The annual assessment of administrative personnel is mainly carried out according to the requirements of the state and the college on the post responsibilities of various personnel. The content mainly includes five aspects: morality, ability, diligence, performance, and integrity, focusing on the actual performance of the work. The specific contents are as follows:

(1) Morality: it mainly assesses the political and ideological performance, social ethics, and professional ethics of administrative personnel.

(2) Ability: it mainly evaluates the professional level, the application and play of management ability, the improvement of the professional technical level, and the renewal of knowledge in line with the responsibilities of administrative posts.

(3) Diligence: it mainly assesses the working attitude, diligence and professionalism of administrative personnel, and their compliance with labor discipline.

(4) Achievements: it mainly assesses the performance of post responsibilities by administrative personnel, the quantity, quality, and efficiency of work tasks, the level of achievements, and social and economic benefits.

(5) Integrity: it mainly assesses the administrative personnel's compliance with discipline and law, selfdiscipline, integrity, and self-discipline.

3.2.4. Assessment Criteria. The annual assessment of administrative personnel should determine the corresponding assessment focus according to the basic requirements of management education and service education, the basic performance of political ideology and professional ethics, and in combination with the characteristics of each department.

(1) The assessment of party and government managers focuses on honesty and self-discipline, policy and theoretical level, work ability, work attitude, work style, cooperation spirit, work performance, etc.

(2) The assessment of administrative professional technicians focuses on the attitude of serving teaching and scientific research, professional and technical level, performance of post responsibilities, etc.

(3) For personnel who concurrently hold multiple positions, their performance of main post responsibilities shall be assessed, and their other work shall be taken into account.

The assessment results are divided into three grades: excellent, qualified, and unqualified. Among them, the number of people with excellent grades is less than $15 \%$ of the total number of people in the department. The basic criteria for assessing excellence, qualification, and disqualification are as follows.

3.2.5. Excellent. Morality: it supports the line, principles, and policies of the party and the state, has a strong sense of responsibility and exemplary compliance with national laws, regulations, and various rules and regulations, and is loyal to the educational cause of the party and the people. As a leading cadre above the deputy section chief, the personnel of the department have no fighting or violation of social security management, and all the staff of the department under management have responded well.

Ability: strong working ability and greatly improved business ability.

Diligence: hardworking, without being criticized in a notice throughout the year, no absenteeism, personal leave within 7 days, and sick leave within 15 days.

Achievements: well perform the post responsibilities and complete the work tasks specified by the employed post with high quality and full load, innovation, outstanding performance, due diligence, and remarkable achievements in scientific research, management, and logistics services.

Integrity: model compliance with national laws, regulations, and various rules and regulations, honest performance of official duties, and no violation of discipline such as favoritism, corruption, and bribery.

3.2.6. Qualified. Morality: support the line, principles, and policies of the party and the state, and consciously abide by various rules and regulations. Work actively, seriously, and responsibly, be able to complete work tasks without liability accidents. 
Ability: strong working ability, improved professional ability, and basically competent for the administrative position.

Diligence: work actively, seriously, and responsibly, abide by labor discipline, and have no late arrival, early leave, or unexplained absenteeism.

Achievements: perform post responsibilities well and basically complete the work tasks specified by the employed post.

Integrity: be able to abide by national laws, regulations, and various rules and regulations, no violation of discipline and law, and no criticism and punishment throughout the year.

3.2.7. Unqualified. Morality: the political and professional quality is low, the organizational discipline is poor, and the rules and regulations cannot be basically observed.

Ability: difficult to adapt to work requirements and poor performance of post responsibilities.

Diligence: absenteeism or failure to return without justified reasons for more than 10 consecutive days, or absenteeism for more than 10 days in a year, or leaving without the approval of the college.

Achievements: poor performance of post responsibilities, weak sense of responsibility, and unable to complete work tasks.

Integrity: those who violate discipline and law, cause adverse consequences, commit serious mistakes, and are punished by the administrative record of major demerit or serious warning within the party.

3.2.8. Design Method of Assessment Index Weight System. There are generally many methods to design the performance appraisal index system [22-24], such as the Delphi method, ranking method, direct judgment method, analytic hierarchy process, weight factor judgment table method, fuzzy coordinated decision-making method, and frequency statistics method. This study uses the analytic hierarchy process (AHP) to design the weight of each index.

(1) Judgment matrix: AHP organizes and hierarchizes the problems by analyzing the factors and related relationships contained in the complex system and constructs an analytic hierarchy process structure model. Generally, the factors contained in the problems are divided into the highest level, the middle level, and the lowest level, that is, the target level, the criterion level, and the index level [25-27]. Assuming that $B_{k}$ in the structural model is used as a criterion, the element value of the matrix is judged by comparing the element $C_{k i}, \ldots, C_{k m}$ of the next level. That is to say, $a_{\mathrm{ij}}$ represents the ratio of the influence of factors $C_{k i}$ and $C_{k j}$, and then, the judgment matrix is as follows:

$$
\mathbf{A}=\left[\begin{array}{cccc}
a_{11} & a_{12} & \cdots & a_{1 n} \\
a_{21} & a_{22} & \cdots & a_{2 n} \\
\cdots & \cdots & \cdots & \cdots \\
a_{m 1} & a_{m 2} & \cdots & a_{m n}
\end{array}\right]
$$

The above element $a_{i j}$ of the judgment matrix represents the relative importance of the elements $C_{k i}$ to $C_{k j}$ from the perspective of the evaluation criterion $B_{k}$, and its value can be determined by the " $1-9$ " scale method.

(2) Index weight vector: the maximum eigenvalue and eigenvector are calculated by the square root method, and the calculated eigenvector is the decision index weight vector [28-30]. The specific calculation steps are as follows:

Step 1: calculate the product $\mathbf{M}_{i}$ of each row element of the judgment matrix:

$$
\mathbf{M}_{i}=\prod_{j=1}^{m} a_{i j}, \quad i=1,2, \ldots, m .
$$

Step 2: calculate the $m$ root $\bar{W}_{i}$ of $\mathbf{M}_{i}$ :

$$
\bar{W}_{i}=m \sqrt{\mathbf{M}_{i}} .
$$

Step 3: normalize the vector $\overline{\mathbf{W}}=\left[\bar{W}_{1}, \bar{W}_{2}, \ldots, \bar{W}_{m}\right]^{T}$ :

$$
W_{i}=\frac{\bar{W}_{i}}{\sum_{j=1}^{m} \bar{W}_{j}}, \quad i=1,2, \ldots, m .
$$

Then, $\mathbf{W}=\left[W_{1}, W_{2}, \ldots, W_{m}\right]^{T}$ is the required feature vector. The feature vector is the weight vector of the element $C_{k 1}, C_{k 2}, \ldots, C_{k m}$ under the $B_{k}$ criterion [31].

Step 4: calculate the largest characteristic root $\lambda_{\max }$ of the judgment matrix:

$$
\lambda_{\max }=\frac{1}{m} \sum_{i=1}^{m} \frac{\left(\mathbf{A} W_{i}\right)}{W_{i}} .
$$

In formula (5), $\left(A W_{i}\right)$ represents the $i$ element of the vector AW. $A W$ is expressed as follows:

$$
\begin{aligned}
\mathbf{A W} & =\left[\begin{array}{c}
(A W)_{1} \\
(A W)_{2} \\
\cdots \\
(A W)_{m}
\end{array}\right] \\
& =\left[\begin{array}{cccc}
a_{11} & a_{12} & \cdots & a_{1 n} \\
a_{21} & a_{22} & \cdots & a_{2 n} \\
\cdots & \cdots & \cdots & \cdots \\
a_{m 1} & a_{m 2} & \cdots & a_{m n}
\end{array}\right]\left[\begin{array}{c}
W_{1} \\
W_{2} \\
\cdots \\
W_{m}
\end{array}\right] .
\end{aligned}
$$


(3) Consistency test: due to the complexity of objective things or one-sided understanding of things, it is necessary to test the consistency and randomness of the judgment matrix whether the eigenvector (weight) obtained through the constructed judgment matrix is reasonable. The test formula is as follows:

$$
C_{R}=\frac{C_{I}}{R_{I}} .
$$

In formula (7), $C_{R}$ is the random consistency ratio of the judgment matrix and $R_{I}$ is the average random consistency index of the judgment matrix. $R_{I}$ is obtained from a large number of experiments. For the low-order judgment matrix, the value of $R_{I}$ is shown in Table 1 .

$C_{I}$ is expressed as the consistency index of the judgment matrix [32-34], which is as follows:

$$
C_{I}=\frac{1}{m-1}\left(\lambda_{\max }-m\right)
$$

In formula (8), $m$ is expressed as the order of the matrix. When $C_{I}<0.1$, the judgment matrix is considered to have satisfactory consistency, indicating that the weight distribution is reasonable. Otherwise, the judgment matrix needs to be adjusted until a satisfactory consistency is achieved.

\subsection{Feasibility Analysis}

(1) Economic feasibility: it mainly compares the funds invested in the development of the new system with the economic benefits brought by the system after it is put into use to confirm whether the new system will bring certain economic benefits to the college. At present, computers are equipped in all departments, and the modern technology center has relevant equipment, and a group of professional teachers and technical teams. To develop this system, you only need to buy relevant software and pay $R \& D$ personnel. The development of the system will promote the reform and improvement of the administrative staff assessment system of the college and promote the long-term development of the college, and the benefits are far greater than the required expenses. Therefore, the system is economically feasible.

(2) Operational feasibility: the college administrative personnel assessment management system is mainly to assist the personnel department in the assessment of administrative personnel. The operation is simple. Users can quickly be familiar with the functions of each module of the system. Moreover, the system can integrate the scores of all assessors and automatically generate the assessment results, saving time, manpower, and material resources. In addition, the system has good compatibility, which can be applied under general application system conditions, and colleges and universities also have these conditions. Therefore, the system is feasible in operation.
(3) Legal feasibility: the design of this system is carried out within the scope permitted by law and does not involve any aspects that conflict with the law, such as contract, liability, or copyright infringement. Therefore, the system is legally feasible.

(4) Technical feasibility: it is to measure whether the required technology is available according to the objectives of the new system, mainly including four aspects: whether the current relevant technology can support the developed new system and the number and level of new system developers, namely human resources, and hardware and software resources.

To sum up, the design and development of this system meet the technical and hardware conditions. Therefore, it is technically feasible.

\section{Design of Performance Appraisal Management System for Administrative Personnel in Colleges and Universities}

4.1. System Architecture Design. To realize the requirements obtained through the analysis of real objects, this study adopts the hybrid cloud architecture [35] and B/S mode based on each component as a service model and uses the J2EE development framework with the advantages of strong portability, security, and stability [36]. A basic information management subsystem for administrative personnel, a performance appraisal information management subsystem, an information analysis and data mining subsystem, and a platform system management subsystem are developed. XML technology and database technology are used to integrate the system with the performance appraisal management system of administrators in colleges and universities. The overall architecture of the system is shown in Figure 2.

The system is equipped with four types of authorized users: ordinary users, administrative personnel data administrators, performance appraisal data administrators, and system super administrators. All subsystems are deployed on the public cloud and the private cloud, respectively. VPN is established between the public cloud and the private cloud through password technology to realize interoperability. Among them, the clients of the basic information management subsystem of administrative personnel, the performance appraisal information management subsystem, and the information analysis and data mining subsystem are deployed on the public cloud, ordinary users and data administrators realize data entry and query through these clients, and the platform system management subsystem, all functional components, and all databases are deployed on the private cloud and realized the actual management function of data information.

4.2. Software Structure Design. Due to the hybrid cloud architecture of each component as a service model, the performance appraisal management system of university administrators based on hybrid cloud is divided into 
TABLE 1: Average random consistency index value of analytic hierarchy process.

\begin{tabular}{lcccccccccc}
\hline Matrix order & 1 & 2 & 3 & 4 & 5 & 6 & 7 & 8 & 9 & 10 \\
\hline$R_{I}$ & 0 & 0 & 0.58 & 0.96 & 1.12 & 1.24 & 1.32 & 1.41 & 1.45 & 1.49 \\
\hline
\end{tabular}

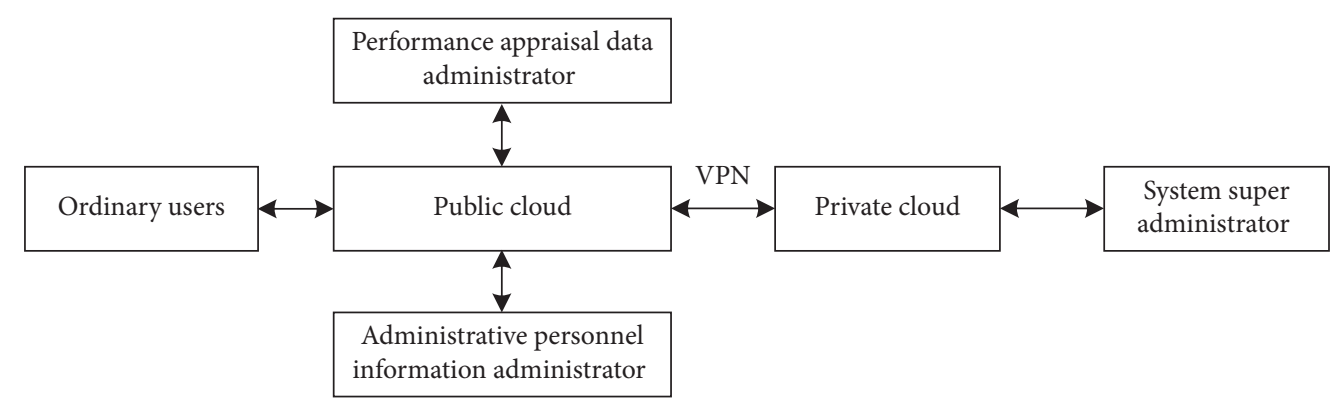

Figure 2: Overall system architecture.

three layers at the software level, which are data cluster, functional component group, and human-computer interaction software group from bottom to top. The system software framework structure is shown in Figure 3.

The data cluster is implemented in the system support database server, which is specifically composed of administrative personnel basic information database, performance appraisal information database, platform system dictionary database, platform system operation management database, and other personnel information management system interface database, and is deployed on the private cloud. The functional component group is realized by many functional components, specifically including administrative personnel basic information management functional components, performance appraisal information management functional components, information analysis and data mining functional components, platform system management functional components, and XML data interface functional components. Among them, XML data interface and information analysis and data mining functional components are deployed in the public cloud, and other functional components are deployed in the private cloud. The human-computer interaction software group is a group of interface programs realized by HTML + JSP, and the corresponding functions are realized by calling functional components. The interface programs related to platform system management are deployed in the private cloud and others in the public cloud.

4.3. System Function Design. The main functions of the whole assessment management system are divided into five modules: personnel management, assessment questionnaire management, assessment management, report output, and statistical query. The functional structure of the system is shown in Figure 4.

(1) Personnel management: evaluation object maintenance, evaluation appraiser maintenance, and administrator maintenance.
(2) Appraisal questionnaire management: questionnaire maintenance, answer maintenance, questionnaire publishing, and judgment matrix setting.

(3) Appraisal management: appraisal indicator maintenance, indicator weight calculation, and personnel appraisal.

(4) Report output: statistics report output.

(5) Statistics query: result statistics, questionnaire statistics, and statistics result query.

4.4. Data Flow Diagram Design. The data flow diagram is the main tool to describe the logical function of the system. Through several specific symbols, it can comprehensively reflect the overall situation of information use, processing, transmission, and storage in the system. The data flow diagram is an effective tool for system structural analysis. It abstractly describes the system data processing, but it cannot express the details of each processing. Therefore, it is necessary to further supplement the data flow and processing in the data flow diagram, which is the data dictionary and transformation logic description. The appraiser data flow chart includes the administrative personnel, leaders in charge, and service objects of the same department. The appraiser needs to enter the user name and password to log in to the system, manage his own basic information, and fill in comments, opinions, and query comments. The data flow chart of administrative personnel needs to enter the user name and password to log in to the system, manage their basic information, fill in self-evaluation and management summary, modify personal information, and query the evaluation content.

4.5. E- $R$ Drawing Design. E- $\mathrm{R}$ method is the abbreviation of "entity relation method." It is an effective method to describe the conceptual structure model of the real world. It uses a rectangle to represent the entity type, and the entity name is written in the rectangular box. Ellipses are used to represent the properties of entities, and undirected edges 


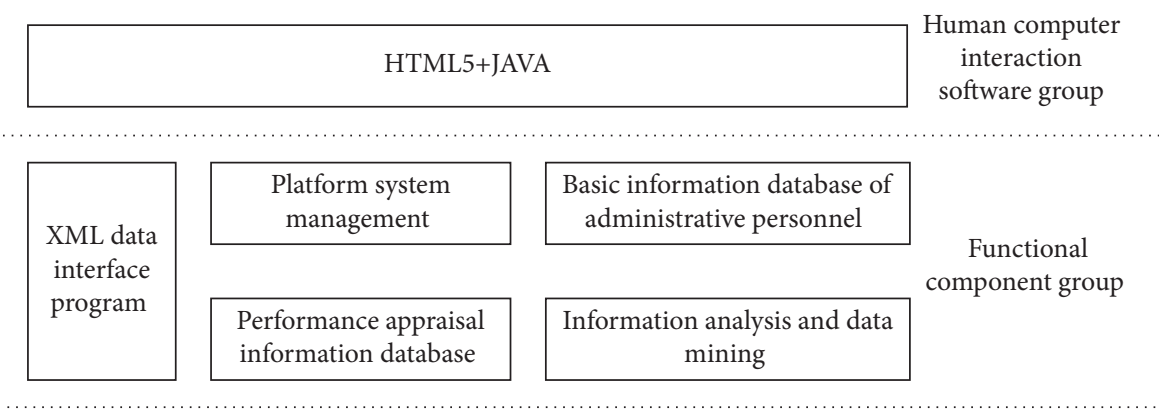

\begin{tabular}{|l|c|c|}
\hline $\begin{array}{c}\text { Basic information data of } \\
\text { administrative personnel }\end{array}$ & $\begin{array}{c}\text { Interface data of other personnel } \\
\text { information management system }\end{array}$ \\
\hline $\begin{array}{c}\text { Platform system } \\
\text { dictionary data }\end{array}$ & $\begin{array}{c}\text { Performance appraisal } \\
\text { information data }\end{array}$ & $\begin{array}{c}\text { Platform system operation } \\
\text { management data }\end{array}$ \\
\hline
\end{tabular}

Data cluster

Figure 3: System software framework structure.

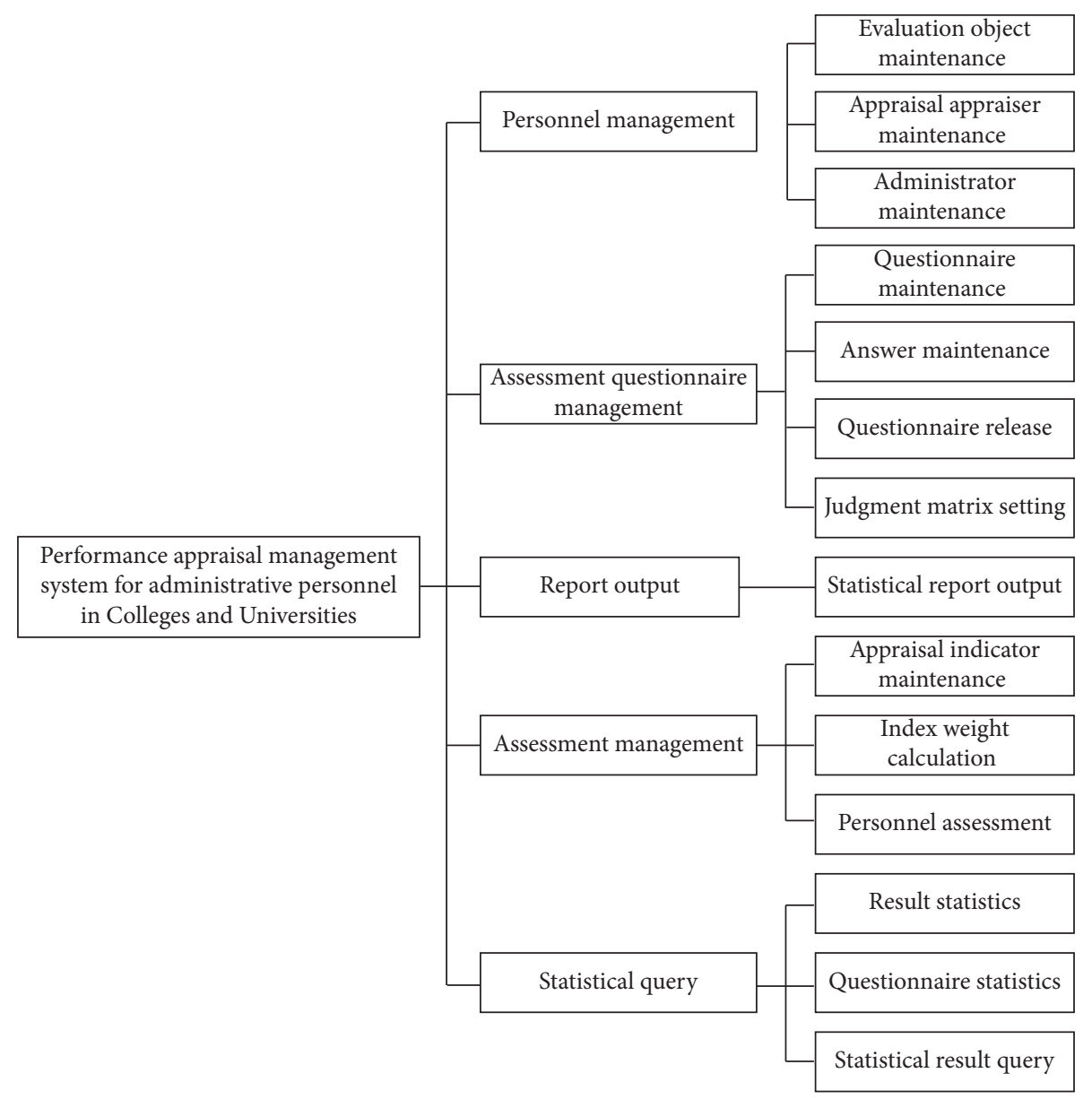

FIGURE 4: System function structure diagram.

are used to connect them with the corresponding entity types. Diamond is used to indicate the connection between entity types, write the contact name in the diamond box, connect with relevant entity types with undirected edges, and mark the type of connection $(1: 1,1: n$, or $M: n)$ next to undirected edges. The overall E-R diagram of the system is shown in Figure 5.

\section{System Test Results and Analysis}

5.1. Setting System Test Environment. To test the effectiveness of the designed performance appraisal management system for university administrators based on hybrid cloud, a trial operation was carried out in a university, and several staff were arranged to participate in the test. Problems found 


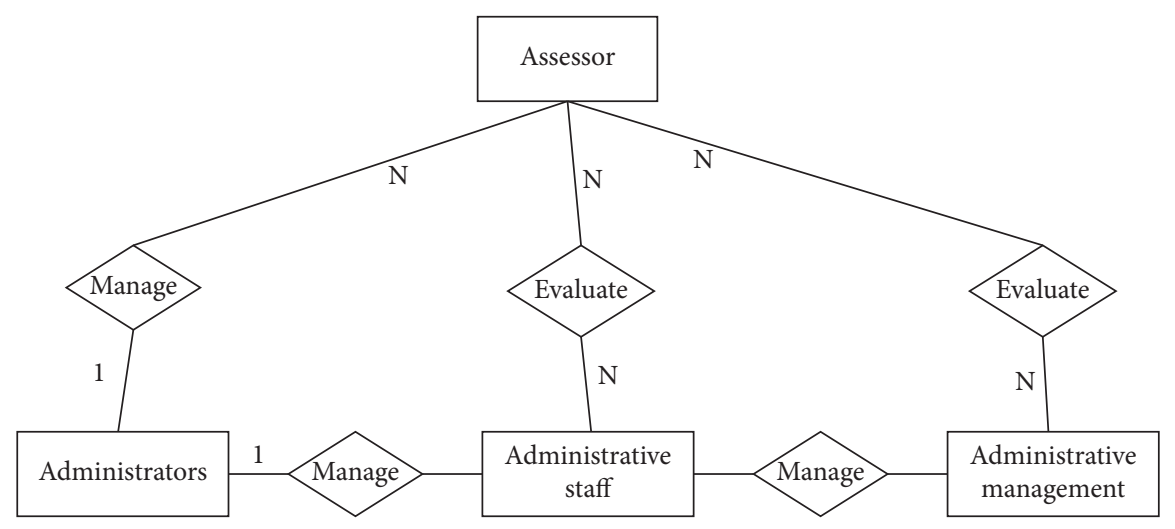

Figure 5: Overall E-R diagram of the system.

through test collection shall be updated and corrected in time during trial operation. When testing, the staff try to operate according to the real business scenario, write corresponding test cases for each module, find problems, and collect feedback, using CentOS 6.5 operating system, Apache + tomcat, MATLAB application software, and MySQL 5.6 database software. The test method of this project adopts black box testing. From the perspective of actual users, according to the software specifications (from demand analysis), software testers test the software functions by inputting various relevant data and observing the output results, regardless of the internal operation principle of the software and how to realize the program, so as to find its defects.

5.2. Test Methods. The test indexes are system functionality, occupancy rate, and response time. The higher the qualified rate of the system function is, the lower the CPU occupancy rate is. The better the real-time performance is, the better the system application performance is. The methods of reference [8], the methods of reference [9], and the proposed methods are compared to verify the performance of the proposed method. For the simulation experiments designed in this study, the simulation software is used to test the application effects of different methods. The simulation software is MATLAB 2020b. The above 3 methods are input into the simulation software to simulate the application and output the test results.

5.3. System Functional Test Results. To verify the functionality of the system, the system function test status is taken as the evaluation index, and the test status is qualified, which indicates that the system functionality designed by the method is good. By comparing the methods of reference [8], the methods of reference [9], and the proposed methods, the system functional test results of different methods are shown in Table 2.

According to the data in Table 2, the function test status of assessment management in the system function test status of the methods of reference [8] is unqualified, and its error type is function error. In the system function test status of the method of reference [9], the function test status of the examination questionnaire management is unqualified, and its error type is syntax error. The system function test status of the proposed method is qualified, which indicates that the system function designed by the proposed method is good.

5.4. System Occupancy Test Results. To further verify the occupancy rate of the system designed by the proposed method, the methods of reference [8], the methods of reference [9], and the proposed method are compared, respectively, and the comparison results of the system occupancy rates of different methods are obtained, as shown in Figure 6.

Analyzing Figure 6 shows that as the number of administrative staff increases, the system occupancy rate of different methods increases. When the number of administrative personnel is 250 , the system occupancy rate of the methods of reference [8] is $15.5 \%$, the system occupancy rate of the methods of reference [9] is $11 \%$, and the system occupancy rate of the proposed method is only $4.5 \%$. It can be seen that, compared with the methods of reference [8] and the methods of reference [9], the system occupancy rate of the proposed method is lower.

5.5. System Real-Time Test Results. On this basis, the realtime performance of the proposed method is further verified, and the system response time is taken as the evaluation index. Among them, the shorter the system response time, the higher the real-time performance of the system. The methods of reference [8], the methods of reference [9], and the proposed methods are compared, respectively, and the system real-time comparison results of different methods are obtained, as shown in Figure 7.

By analyzing Figure 7, it can be seen that with the increase in the number of administrative personnel, the system response time of different methods increases. When the number of administrative personnel is 250 , the system response time of the methods of reference [8] is $18 \mathrm{~s}$ and the system response time of the methods of reference [9] is 21.5 $\mathrm{s}$, while the system response time of the proposed method is only $9.6 \mathrm{~s}$. It can be seen that the system response time of the proposed method is shorter than that of the methods of reference [8] and the methods of reference [9], indicating that the system has high real-time performance. 
TABLE 2: System functional test results of different methods.

\begin{tabular}{|c|c|c|c|c|c|c|}
\hline \multirow{2}{*}{ Different modules } & \multicolumn{2}{|c|}{ The proposed method } & \multicolumn{2}{|c|}{ The methods of reference [8] } & \multicolumn{2}{|c|}{ The methods of reference [9] } \\
\hline & Test status & Error type & Test status & Error type & Test status & Error type \\
\hline Personnel management & Qualified & Nothing & Qualified & Nothing & Qualified & Nothing \\
\hline Assessment questionnaire management & Qualified & Nothing & Qualified & Nothing & Unqualified & Syntax error \\
\hline Assessment management & Qualified & Nothing & Unqualified & Function error & Qualified & Nothing \\
\hline Report output & Qualified & Nothing & Qualified & Nothing & Qualified & Nothing \\
\hline Statistical query & Qualified & Nothing & Qualified & Nothing & Qualified & Nothing \\
\hline
\end{tabular}

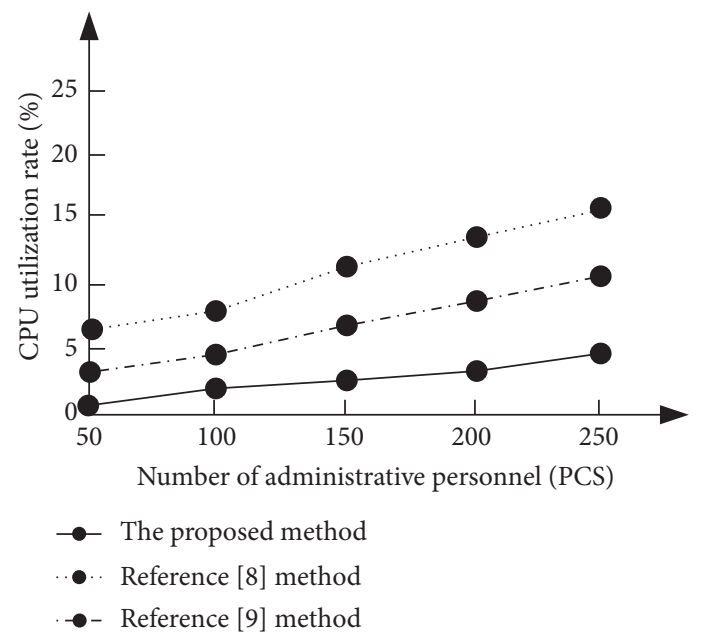

FIGURE 6: Comparison results of system occupancy rate of different methods.

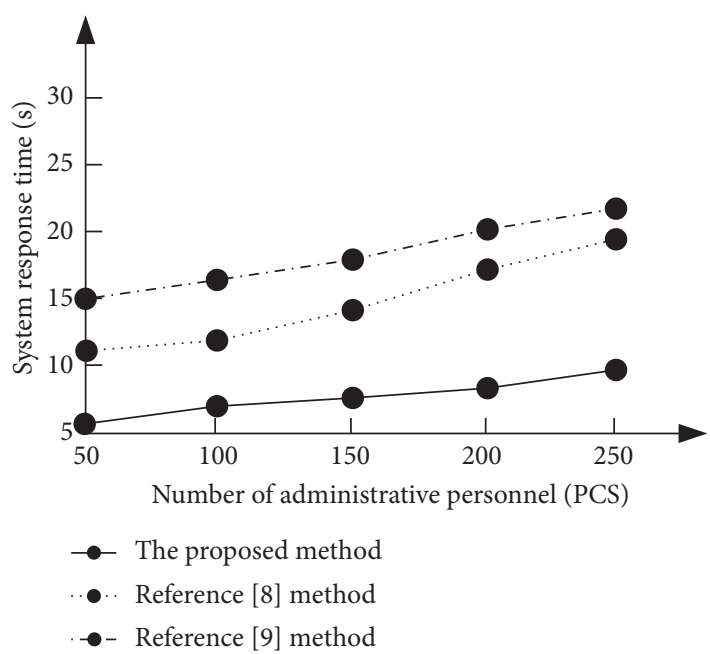

FIGURE 7: Comparison results of system real-time performance of different methods.

\section{Conclusion}

Performance appraisal is an effective means of modern management in colleges and universities. If it can be used reasonably and effectively, the overall efficiency and performance of colleges and universities will be improved without increasing the input of human capital. The performance appraisal management system based on hybrid cloud is designed in this study, which fully displays the advantages of hybrid cloud technology. According to the characteristics of hybrid cloud technology, the overall functional requirements and feasibility of the system are analyzed to optimize the system application and reduce the CPU usage. Using hybrid cloud architecture and B/S model, the basic information management subsystem and performance evaluation information management subsystem are developed, and the hardware design is completed. In the part of software design, data flow graph and E-R graph are introduced to optimize the real-time performance of the system. 
However, in the performance appraisal management system of university administrators, due to the limitations of technical level and the complexity of the work content, specific posts, positions, influencing factors, and service objects of university administrators, the system has not fully considered the relevant factors, and many problems need to be further studied and discussed in specific practice. Therefore, in the next research, we should also consider the division of assessment results and the selection of weight proportion, the division of administrative personnel types, and the differences in assessment indicators and weights according to the changes in the actual situation.

\section{Data Availability}

The raw data supporting the conclusions of this article will be made available by the author, without undue reservation.

\section{Conflicts of Interest}

The author declares that there are no conflicts of interest regarding this work.

\section{Acknowledgments}

This work was supported by the Research and Implementation of Personnel Management System Design Based on B/S Frame (MK2021002).

\section{References}

[1] N. Yadav, "Application of system dynamics methodology in performance management system: a case study of Indian automotive firm," International Journal of Business Performance Management, vol. 21, no. 4, pp. 385-399, 2020.

[2] S. Joomunbaccus, "Investigating the intention to use an electronic performance management system at XYZ holdings limited: towards a revised technology acceptance model," Archives of Business Research, vol. 9, no. 1, pp. 75-96, 2021.

[3] F. A. Yovan, "Decision support system for flood risk assessment and public sector performance management of emergency scenarios," International Journal of Public Sector Performance Management, vol. 1, no. 1, Article ID 10026215, 2020.

[4] T. B. Febrian and A. Simangunsong, "Decision support system employee performance appraisal method using topsis," Journal of Computer Networks, Architecture, and HighPerformance Computing, vol. 2, Article ID 47709, 2020.

[5] J. P. Pereira, E. Natalya, and I. Slesarenko, "The analysis of competency model for a performance appraisal system in the management of food service industry," Advances in Intelligent Systems and Computing, vol. 1137, pp. 162-171, 2020.

[6] W. He, L. Chen, and W. Liu, "Does new performance appraisal system (EVA) affect earnings management?" Nankai Business Review International, vol. 11, no. 2, pp. 191-216, 2020.

[7] J. Liu, C. Wang, and Y. Wu, "Construction and optimization of higher education management system based on Internet video online technology," Scientific Programming, vol. 2021, no. 1, Article ID 5520662, 11 pages, 2021.

[8] B. Z. Nobari, A. Gholipour, E. Ebrahimi, and A. Shoja, "Employee performance appraisal system development in the national library and archives of Iran (NLAI): soft operational research approach," Performance Measurement and Metrics, vol. 22, 2021, ahead-of-print(ahead-of-print).

[9] M. C. Demartini and D. Otley, "Beyond the system vs. package dualism in performance management systems design: a loose coupling approach," Accounting, Organizations and Society, vol. 86, Article ID 101072, 2020.

[10] E. Barbierato, L. Campanile, M. Gribaudo, M. Iacono, M. Mastroianni, and S. Nacchia, "Performance evaluation for the design of a hybrid cloud based distance synchronous and asynchronous learning architecture," Simulation Modelling Practice and Theory, vol. 109, Article ID 102303, 2021.

[11] M. Bouache, "Hybrid cloud: workload placement performance," Hybrid Cloud Migration, vol. 20, no. 9, pp. 135-139, 2020.

[12] T. Rajagopal, M. Venkatesan, and A. Rajivkannan, “An improved efficient dynamic load balancing scheme under heterogeneous networks in hybrid cloud environment," Wireless Personal Communications, vol. 111, no. 4, pp. 1837-1851, 2020.

[13] A. Yousfi, M. Hafid, and A. Zellou, "xMatcher: matching extensible markup language schemas using semantic-based techniques," International Journal of Advanced Computer Science and Applications, vol. 11, no. 8, 2020.

[14] W. C. Hsu and I. E. Liao, "UCIS-X: an updatable compact indexing scheme for efficient extensible markup language document updating and query evaluation," IEEE Access, vol. 8, Article ID 176375, 2020.

[15] G. Polancic and B. Orban, "A BPMN-based language for modeling corporate communications," Computer Standards \& Interfaces, vol. 65, pp. 45-60, 2019.

[16] V. Karimli, "Administrative management theory at high educational institutions and its following stages," International Journal of Management, vol. 11, Article ID 34218, 2021.

[17] Y. Tang, D. Xie, W. Zhang, X. Guan, and Y. Han, "Research on the informationization construction of college admission management," Canadian Social Science, vol. 15, no. 2, pp. 273-278, 2019.

[18] M. S. Jani, J. Shahril, M. I. Muszali, R. Adnan, and S. A. Mai, "Administrative management quality standard and teachers" practices compliance on school sports safety," International Journal of Academic Research in Progressive Education and Development, vol. 10, no. 2, pp. 648-664, 2021.

[19] R. K. Upadhyay, K. R. Ansari, and P. Bijalwan, "Performance appraisal and team effectiveness: a moderated mediation model of employee retention and employee satisfaction," Vision: The Journal of Business Perspective, vol. 24, no. 4, pp. 395-405, 2020.

[20] E. Y. Huang, D. Paccagnan, W. Mei, and F. Bullo, "Assign and appraise: achieving optimal performance in collaborative teams," Social and Information Networks, vol. 22, Article ID 09817, 2020 https://arxiv.org/abs/2008.09817.

[21] S. Ling, "Research and practice of performance appraisal of specialist nursing staff," Advanced Journal of Nursing, vol. 2, no. 2, pp. 313-318, 2021.

[22] S. Susanto and N. K. Darmasetiawan, "Designing a performance appraisal system for management consultant office "D"," Dinasti International Journal of Digital Business Management, vol. 1, no. 3, pp. 361-374, 2020.

[23] L. J. Xiao and Z. X. Xun, "Performance appraisal of technological innovation in military-civilian enterprises-empirical evidence from jiangsu military-civilian integration enterprises," International Journal of Business and Management, vol. 15, no. 11, p. 79, 2020. 
[24] L. Jin, J. Liu, and D. Kong, "Evaluation of the incorporation of gross ecosystem product into performance appraisals for ecological compensation," Acta Ecologica Sinica, vol. 39, no. 1, pp. 24-36, 2019.

[25] B. Zhang, C. C. Li, Y. Dong, and W. Pedrycz, "A comparative study between analytic hierarchy process and its fuzzy variants: a perspective based on two linguistic models," IEEE Transactions on Fuzzy Systems, vol. 29, no. 99, Article ID 3018110, 2020.

[26] Z. J. Wang, "Eigenproblem driven triangular fuzzy analytic hierarchy process," Information Sciences, vol. 578, no. 1, pp. 795-816, 2021.

[27] A. Zjw, Y. B. Xuan, and A. Xtj, "And-like-uninorm-based transitivity and analytic hierarchy process with interval-valued fuzzy preference relations," Information Sciences, vol. 539, pp. 375-396, 2020.

[28] Z. A. Pan, M. A. Teng, J. A. Gang, and Z. W. Yang, "An efficient interference steering matrix estimation scheme for weight vector correction," Digital Signal Processing, vol. 114, Article ID 103039, 2021.

[29] X. Ma, Y. Yu, X. Li, Y. Qi, and Z. Zhu, "A survey of weight vector adjustment methods for decomposition-based multiobjective evolutionary algorithms," IEEE Transactions on Evolutionary Computation, vol. 24, no. 4, pp. 634-649, 2020.

[30] Y. Xue and L. Zhang, "Laplacian pair-weight vector projection for semi-supervised learning," Information Sciences, vol. 573, no. 2, pp. 1-19, 2021.

[31] E. Li and R. Chen, "Multi-objective decomposition optimization algorithm based on adaptive weight vector and matching strategy," Applied Intelligence, vol. 50, no. 6, pp. 4206-4222, 2020.

[32] T. Wahyuningrum, A. Azhari, A. Azhari, and S. Suprapto, "Modified LFPP to improve the accuracy of matrix pairwise comparison consistency index in the usability evaluation," International Journal of Intelligent Engineering and Systems, vol. 13, no. 3, pp. 397-406, 2020.

[33] J. Aguarón, M. T. Escobar, and H. Jiménez, "Reducing inconsistency measured by the geometric consistency index in the analytic hierarchy process," European Journal of Operational Research, vol. 288, pp. 576-583, 2021.

[34] X. Chen, L. Peng, Z. Wu, and W. Pedrycz, "Controlling the worst consistency index for hesitant fuzzy linguistic preference relations in consensus optimization models," Computers \& Industrial Engineering, vol. 143, Article ID 106423, 2020.

[35] H. Pang and W. Zhao, "Big data efficient hybrid cloud storage model and algorithm simulation under 5 G network," Computer Simulation, vol. 37, no. 7, pp. 350-353+379, 2020.

[36] Y. Zhao and R. Wang, "Design and implementation of scitech project management system based on J2EE spring MVC framework," Shanxi Science and Technology, vol. 143, Article ID 106423, 2019. 